\section{Investigate the Conceptual Framework for Developing Family- centered Early Interventions for the Cognitive Functions of 3 to 5 Year old Children}

\author{
Alireza Mosavi Amjad ${ }^{1}$, Ahmad Ghazanfari ${ }^{2 *}$, Salar Faramarzi ${ }^{3,4}$
}

Iranian Evolutionary and Educational Psychology Journal

December 2020: 225-238

(C) University of Hormozgan Publication 2020 DOI: 10.29252/ieepj.2.4.225 http://ieepj.hormozgan.ac.ir

\begin{abstract}
The purpose of this research was to investigate the conceptual framework for developing family-centered early interventions for the cognitive functions of 3 to 5-year-old children in Yasuj. Using the convenience sampling method, the researchers analyzed all the foreign and domestic studies conducted until 2018. Also, the snowball sampling method was used to select ten experts to evaluate the components. The data were analyzed by thematic analysis using Nvivo software. Data analysis revealed four organizing themes, including attention, memory, language, and executive functions. Seventeen basic themes that constituted the organizing themes were extracted to develop a family-centered intervention program for cognitive functions. The basic themes were maintaining attention, sustained attention, divided attention, focused and selective attention for the theme of the organizer of attention; visual, auditory and working memory for the theme of the organizer of the memory; expressive and receptive language for the theme of the language and basic themes of planning, emotional control, time management, flexibility, metacognition, response inhibition and organization for the theme of the organizer of executive functions. To validate the thematic model, the researchers designed a questionnaire and gave it to the second group of experts, and the coding reliability was confirmed by Holsti's method. This package can pave the way for parents of at-risk children and children with developmental delays. It can also help enhance the cognitive functions of normal children.
\end{abstract}

Keywords: Early intervention, Family-centered, Cognitive functions

\title{
Introduction
}

Cognitive functions are high-level cognitive processes that help individuals perform life tasks at every stage of development. They are neural processes involved in acquiring, processing, storage, and utilizing information (Shettleworth, 2010). These functions are the link between the brain's behavior and structure and include a wide range of abilities, e.g., planning, attention, response inhibition, problem-solving, simultaneous task completion, and cognitive flexibility (Madrigal, 2008). Scientific findings revealed that these functions are formed during the child's developmental period; they appear from the earliest stages of growth (probably the end of the first year of life); they grow gradually, and significant changes occur in them from the age of two to five. According to the theory of cognitive complexity and control, the evolution of these processes can be understood by age-dependent growth and in the context of the maximum complex operations and rules that the child

1. PhD student of Psychology of education, Islamic Azad University, Shahr kord Branch, (mosavi197420@yahoo.com).

2. Associate professor of Psychology, Islamic Azad University, Sahr kord Branch*Corresponding author email: aghazan5@yahoo. $\underline{\mathrm{com}}$

3. Invhted Associate professor of Psychology, Islamic Azad University, Sahr kord Branch

4. Associate professor of Psychology of Children with Special Needs, University of Isfahan. (salarfara,arzi@yahoo.com). 
can formulate and use to solve the problem (Zelazo, Muller, Frye, Marcovitch, Argitis, \& Bosveski, 2005). Interest in cognitive functions has recently increased, and efforts have been made to understand them more accurately (Hughes, 2011). Blair and Raver (2012) stated that children are different in terms of cognitive functions, which is much more evident with the age of children. It also shows that the environment also affects the development of cognitive functions in addition to neurological factors.

Researchers have recently used various quantitative and qualitative methods to assess the rate of cognitive development in children. What researchers considered in evaluations were standardizing and creating criteria in their normal assessments. Standard assessment of cognitive function is often the primary element of a comprehensive assessment in early childhood. A child's performance during the cognitive assessment may denote important concepts. Access to resources or treatment decisions and ability measurement can be determined based on information obtained from this cognitive assessment. Therefore, getting reliable, valid, and meaningful assessment results and appropriate interpretation of performance is necessary, which begins with the careful selection of tools based on technical conditions and purposeful application (Ellingsen, 2016).

While understanding brain development in the first five years of life has significantly improved (because significant technological advances allow for advanced visualization of brain structure and function), preschool children's assessment failed to keep pace with it (Baron \& Anderson, 2012). Assessing early childhood cognitive ability is challenging for some reasons. For instance, growth changes occur most rapidly during the first five years of life and might be inconsistent in different areas. Furthermore, the behavior might be variable and more sensitive to environmental and situational factors. The development of different skills and abilities in childhood varies, and the rapid and often occasional growth of the central nervous system usually results in dramatic changes in cognitive ability over a very short period of time (Thomas, Thomas, Bosch et al., 2019). Accurate assessment of the concerns related to cognitive function is also tricky due to the limited number of instruments available for young children and the variability of child behavior in various contexts. On the other hand, neglecting this early assessment causes adverse consequences such as delayed identification of early ages delay and neuropsychological disorders. Such delays mitigate the effects of the intervention and early treatment situations that might compensate for deficiencies that become more evident during the primary school years. The possible explanation is that given the significant brain and cognitive development during this period, the preschool years are ideal for family-centered interventions (Baron \& Anderson, 2012).

In timely intervention programs, all rehabilitation and educational services are used to develop the cognitive, language, sensory-motor, emotional-social, and behavioral skills of children under six years of age. In addition to children, these programs take the families into account (Malekpur, 2003). The crucial issue in providing the child and family assessment service is planning an appropriate program for each family and having the utmost engagement of parents (Abedi, 2008). Timely family-centered interventions represent a kind of supportive-educational system that attempts to support, rehabilitate, and educate the child and his family from birth or the first possible opportunity after identifying the child with special needs. Different terms were used for family-centered services, including focused family, family-centered, and family-based; however, family-centered is the most commonly used term (Tart \& Hebert-Murphy, 2007).

The family-centered approach goes beyond integrating content about family-centered services into educational planning to engage family members in education and implementation and considers the family critical in ensuring children's health and well-being. That is why today, attention to growth-related services has shifted 
from a traditional child-centered model to a family-centered model (Barker et al., 2009). Family-centered intervention is based on family system theory, which determines family well-being based on the child's well-being and focuses on the strengths, resources, and capabilities of the child and family. This intervention was gradually developed from family system theory, i.e., based on the two principles of empowerment and help to give in the family-oriented philosophy (Dempsey \& Keen, 2008). Empowerment includes professional communication with the family so that the family retains or acquires a sense of control over the situation and is receptive to the positive changes resulting from behaviors determined by the development of abilities and practices. Because the participation of family members in child care is one of the critical principles in family-centered empowerment, the therapist can provide the client and family members the opportunity to demonstrate the abilities and competencies necessary to meet the child and family's needs. To help individuals and families to take an active role, therapists should emphasize empowerment than helping. Empowerment causes self-confidence, the ability to achieve the goal, and a sense of control over life and change processes, as well as a sense of hope for the future (Teimouri, Alhani \& Kazemnejad, 2014).

According to the Can Child Center for Childhood Disability Research, family-centered interventions are a set of values, attitudes, and approaches to intervention for children with special needs and their families that identify parents as experts in their children's needs and enhance the relationship between parents and service providers and support the role of the family in opting for the services provided to the child. In this definition, each family is unique, and its role in the child's life is always constant and is aware of the child's abilities and needs and cooperates with service providers to be informed of decisions about their child. To provide service in a family- centered approach, the strengths, abilities and needs of all family members are considered (Law, Hanna \& King et al., 2003).

Remy and Remy (1998) stated that a wide range of activities is designed to enhance the child's growth and health, beginning with a comprehensive assessment of the child, the family potentials, and needs to provide services. The literature confirms that a timely intervention program during the early years of life improves children's growth and development and dramatically neutralizes the impact of risk factors, such as adverse economic and social conditions Makes (Reeves, 2003). In general, research shows that supporting a child's early growth and development has consequences for the child and his/her parents and prepares him/her for further learning and success in life. Postnatal development occurs when children interact with the objects in their surroundings because the environment, successes, and experiences significantly affect the child (Baron $\&$ Anderson, 2012). Given the importance of cognitive functions and the impact of timely interventions, the present study aimed to develop a family-centered intervention package for 3- to 6-year-old children's cognitive functions.

\section{Material and Method}

The present research was qualitative and inductive content analysis. The content analysis method used in this research is based on Attride-Stirling (2001) thematic analysis method, which identifies themes inductively and is based on the basic themes, organizing themes, and universal themes approach. This method deals with the position and type of themes in the thematic network and converts scattered and varied data in the text into rich and detailed data. In this regard, to develop the family-centered interventions package, the previous literature (Table 1) was studied by researchers, and the components related to the purpose of the research 
were identified. The components and the factors that strengthen 3-to-5-year-old children's cognitive functions were extracted and coded by Nvivo. Furthermore, if similar themes existed in the literature, they were used for coding the themes of this study. The identified codes were combined based on the degree of conceptual similarity and were identified as free nodes by the software. Finally, the identified themes were categorized and sorted into basic, organizing, and universal themes based on the researchers' perception. The themes were then refined several times. Some were removed or added to draw a thematic network consisting of a universal theme of cognitive functions and organizing themes of attention, memory, language, and executive functions, as well as their basic themes (Figure 1).

\section{Results}

The themes were identified and extracted by reviewing the literature (Table 1). As can be seen in Table 1, the extracted components include four organizing themes and 17 basic themes, namely attention organizing theme (including the basic themes of focused attention, selective attention, sustained attention, divided attention, and maintaining attention), memory organizing theme (including the basic themes of visual and auditory memory), language organizing theme (including the basic themes of receptive and expressive language) and executive functions organizing theme (including the basic themes of planning, affective control, time management, flexibility, metacognition, response inhibition, and organization).

\section{Organizing themes}

Consistent with the primary aim of the research, which was identifying and extracting the components of timely family-centered interventions for cognitive functions of 3-to-6-year-old children, four organizing themes were extracted, each of which is discussed below:

Attention organizing theme: Studies have shown that most children with cognitive dysfunction are significantly weaker in planning and attention than their healthy peers. They also perform poorly on both consecutive and simultaneous process scales than normal peers and are expected to more likely drop out of school than normal peers (Kirby \& Das, 2005).

Memory organizing theme: The first thing to note is that memory evolves, and as children get older, they use their memory more effectively and efficiently. The second characteristic of memory is that memory comprises different skills. For example, recognizing a person by face is a different memory function compared with preparing for an exam. Both are remembering; however, each demonstrates a different memory skill (Buchanan \& Adolph's, 2002). The point is that memory is not a separate process or structure, yet it is an appropriate explanation for a set of cognitive processes. Memory evolution is also a combination of changes in each of several memory components. The third characteristic of memory is that memory is not a separate intellectual skill but is closely involved in many of the child's intellectual and social endeavors. Memory also plays a crucial role in the complex activities of reading, comprehension, arithmetic, and academic ability (Meltzer, 2018). Regarding memory functions, some researchers have introduced memory as the most sensitive and psychologically influential component of cognitive functions (Eriksson et al., 2015). It should also be noted that memory is very closely related to learning and is even defined in some cases, according to it (Hosseinali zadeh et al., 2019). 
Table 1. Universal, organizing, and basic themes

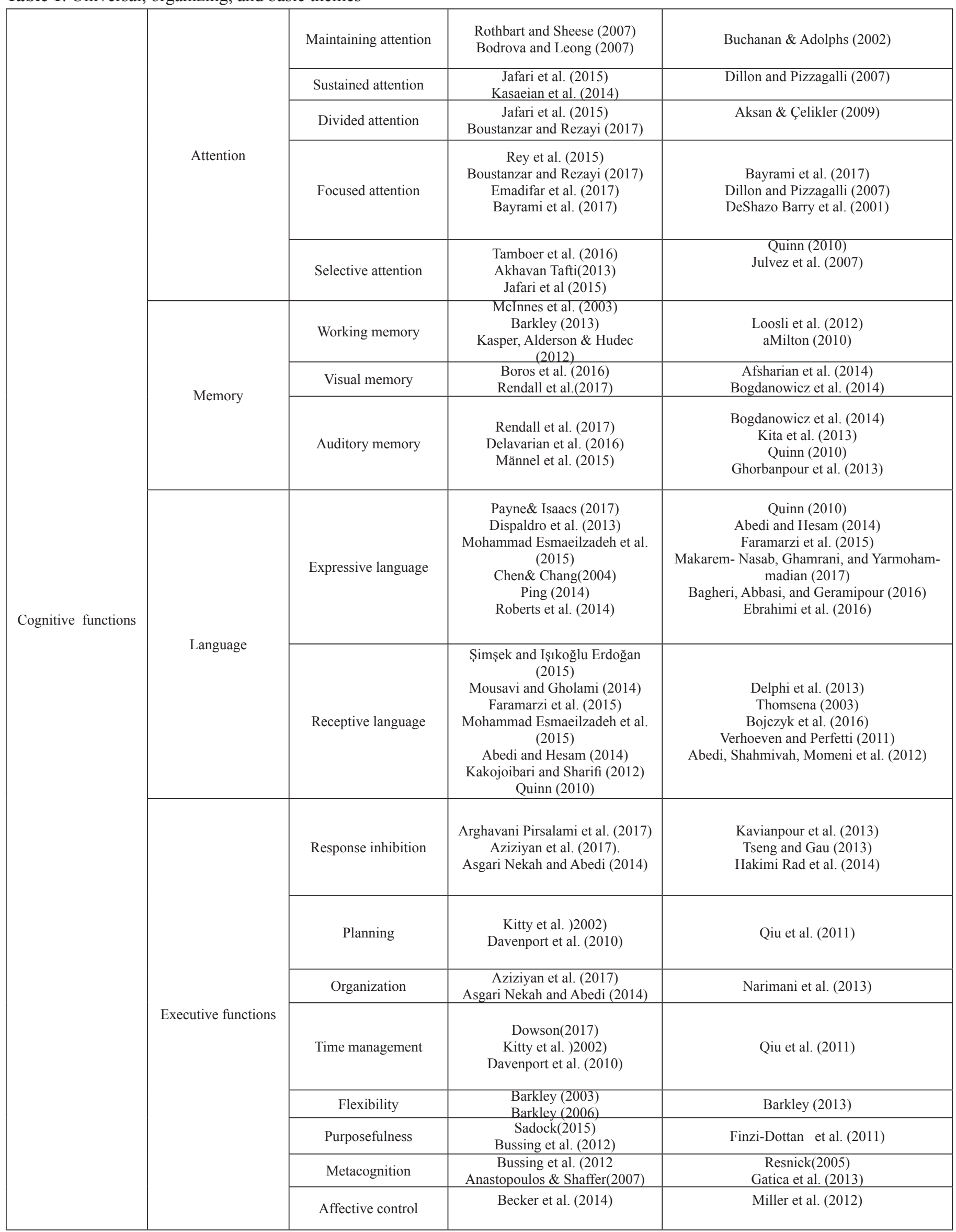


communication process, the clarity of its purpose, and the response rate, compared with normal children, all of which make their interaction different from their normal peers (Roberts, 2011; as cited in Hosseinali zadeh et al., 2019). Language, as the primary tool of human communication with other people in society, plays a significant role in the child's mental development. Language has a dual function; that is, it is both a means of cognition and thought and a means of communication and social life. Delays in language development can affect other developmental functions of the child. The most obvious effects of language developmental delays are delays in learning, neuropsychological problems, and socio-communication problems. Even the most acute state of learning disability is related to language, and language delay is seen in the history of these disorders (Yarmohammadian, 2013).

Executive functions organizing theme: Executive function construct is an umbrella term for various cognitive processes that serve purposeful behavior and actions (Lezak \& Howieson, 2009). Children who suffer from cognitive dysfunction face significant problems with executive functions, especially planning and organizing, working memory, and inhibition (Endlich, 2001).

\section{Validation of the developed package}

Independent coding was used for validating the developed package. This method is commonly used for evaluating and controlling the quality of the content analysis. In the positivist approaches of qualitative research, independent coding is equal to the statistical estimation of internal reliability performed in quantitative content analysis or structured observation (King \& Horrocks, 2010). To estimate the validity of the present study, besides reviewing the literature and extracting themes (basic, organizing, and universal themes), the opinions and guidelines of a group of experts were taken into account. For this purpose, the experts were requested to introduce the major topics based on their work and research experience. Then, their reports and data extracted from Nvivo software were reviewed, and the reliability coefficient was calculated using Holsti's method, whose formula is as follows:

$$
\mathrm{PAO}=2 \mathrm{M} /(\mathrm{n} 1+\mathrm{n} 2)=2.210 / 210+227=0.8
$$

PAO means the percentage of agreement observed (reliability coefficient); $\mathrm{M}$ is the number of accords at the coding site; $\mathrm{n} 1$ is the number of units coded in the first stage, and $\mathrm{n} 2$ is the number of units coded in the second stage. The PAO value varies between zero (no agreement) to one (full agreement). Therefore, the above calculation shows that the research results are highly reliable. Finally, a network of themes was drawn, which can be seen below (Figure 1). 


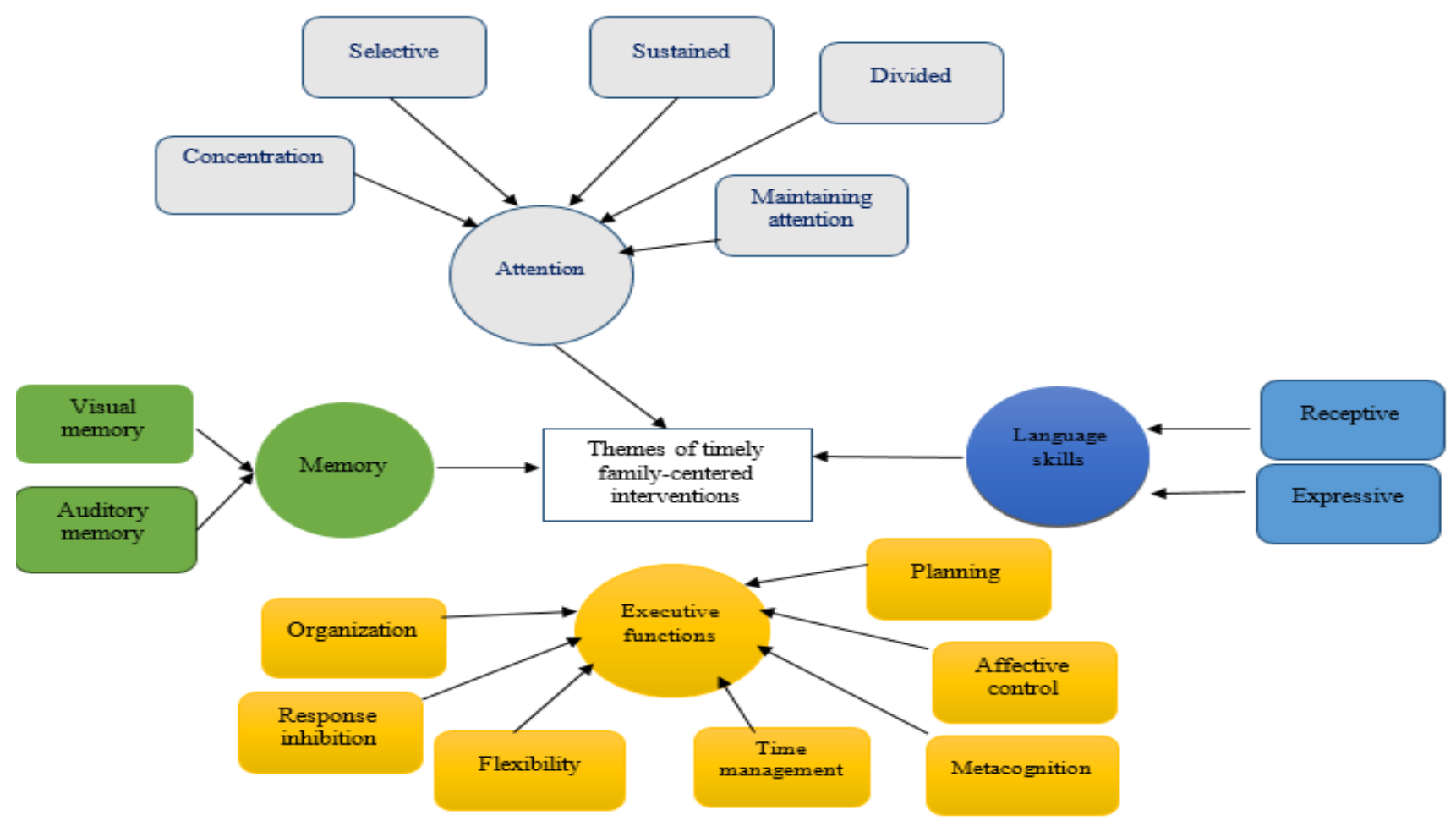

Figure 1. Thematic Network

\section{Discussion}

This study aimed to design and develop a timely family-centered interventions package specific to the cognitive functions of children aged 3 to 6 years. The themes of timely family-centered interventions specific to the cognitive function of children aged 3 to 6 years were obtained by analyzing several Persian and English articles in which different elements of cognitive development were investigated. The most prominent elements were selected and validated using experts' opinions. Finally, the thematic network was drawn in four organizing themes (attention, memory, language, and executive functions) and 17 related basic themes.

According to the results of the studies mentioned in the previous section, it can be concluded that at-risk children experience difficulty in cognitive functions and, in many cases, have delays in some or all components of cognitive function. Cognitive functions enable humans to understand concepts, solve problems, pay attention, memorize, and make decisions, and delays in this area can seriously impair an individual's daily life (Poon-McBrayer \& Wong, 2013). Moreover, defects or delays in cognitive functions can largely affect an individual's function, including (a) slower processing speed; (b) shorter attention span; (c) difficulty in problem-solving and abstract thinking; (d) problems and slowness in storing and retrieving information (Hosseinali zade \& Faramarzi, 2019).

On the other hand, neglecting children's initial examination has adverse effects such as late identification of early ages' delays and psychological, neurological disorders. Such delays mitigate the intervention's impact and early treatment situations that might compensate for deficiencies that become more evident during the primary school years. The possible explanation is that given the significant brain and cognitive development during this period, the preschool years are the ideal age for family-centered interventions (Baron \& Anderson, 2012). Timely family-centered interventions represent a kind of supportive-educational system that attempts 
to support, rehabilitate and educate the child and his family from birth or the first possible opportunity after identifying the child with special needs (Tart \& Hebert-Murphy, 2007). Therefore, the present study package also identified and extracted the components of children's cognitive functions, considering the flexibility of children's brains at a young age and also the importance of enriching their environment, especially under the age of six, and provided training and games to strengthen them.

Therefore, as this package was designed and developed using a scientific method and the related literature, it is expected to be useful for the cognitive functions of children aged 3 to 6 years. This package can also help kindergarten teachers, counseling centers, providers of psychological services, and organizers of parent-child workshops who work with children and their families. One of the limitations of this study was that researchers could not ensure whether all the themes related to children's cognitive functions were identified and extracted.

Declaration of Conflicting Interests: The author(s) declared no potential conflicts of interest with respect to the research, authorship, and/or publication of this article.

Funding: The authors received no financial support for the research, authorship, and/or publication of this article.

Acknowledgements: We are grateful to all the participants who have contributed to this study.

\section{References}

Abedi, A. (2008). Preliminary standardization of NEPSY test and the effectiveness of early interventions on rehabilitation of children with preschool neuropsychological / developmental learning disabilities. $(\mathrm{PhD}$ Dissertation), University of Isfahan, Iran. (Persian)

Abedi, A., \& Malakpoor, M. (2010). Investigation of efficacy of educational - psychological early interventions for improving executive functions and attention of children with neuropsychological learning disabilities. New Educational Approaches, 5(1), 67-88. (Persian)

Abedi, A., Shahmivah Esfahani, A., Momeni, F., \& Shahmivah Esfahani, Y. (2011). Skills needed by children to enter school. Isfahan: Neveshteh Publishing. (Persian).

Akhavan Tafti, M. (2013). A Comparison of auditory selective attention and hearing dominance in students with and without Dyslexia. International Journal of Behavioral Sciences, 7(3), 215-220.

Aksan, Z., \& Çelikler, D. (2009). Pre-School Science Education: The Development and Evaluation of Science Teaching Materials.

Anastopoulos, A. D., \& Shaffer, S. D. (2007). Attention deficit hyperactivity disorder. Handbook of clinical child psychiatry.

Arghavani Pirsalami, M., mosavi nasab, M., \& khezri moghadam, N. (2017). The effectiveness of cognitive empowerment on executive functions (inhibition, updating and shifting) in Sstudents with learning disorder. Biquarterly Journal of Cognitive Strategies in Learning, 5(8), 205-222. (Persian)

Asgari Nekah, S. M., \& Abedi, Z. (2014). The effectiveness of executive functions based play therapy on improving response inhibition, planning and working memory in children with Attention Deficit Hyperactivity Disorder. JCP, 2(1), 41-51. (Persian)

Attride-Stirling, J. (2001). Thematic networks: an analytic tool for qualitative research. Qualitative research, 1(3), 385-405. 
Aziziyan, M., asadzadeh, H., alizadeh, H., dortag, F., \& sadipour, E. (2017). Developing and Implementing an Educational Package for Training Executive Functions and its Effectiveness on underachiever pupils' Academic Achievement. Biquarterly Journal of Cognitive Strategies in Learning, 5(8), 113-137. (Persian).

Bagheri, N., Abbasi, E., \& Geramipour, M. (2016). The impact of language learning activities on the spoken language development of 5-6-year old children in private preschool centers of Langroud. Journal of Family and Research, 8 (31), 67-86. (Persian).

Barker, D. H., Quittner, A. L., Fink, N. E., Eisenberg, L. S., Tobey, E. A., Niparko, J. K., \& CDaCI Investigative Team. (2009). predicting behavior problems in deaf and hearing children: The influences of language, attention, and parent-child communication. Development and Psychopathology, 21(2), 373-392.

Barkley, R. A. (2003). Issues in the diagnosis of attention-deficit/hyperactivity disorder in children. Brain and development, 25(2), 77-83.

Barkley, R. A. (2006). Attention-deficit hyperactivity disorder: A handbook for diagnosis and treatment (3rd ed.). New York: Guilford.

Barkley, R. A. (2013). Distinguishing sluggish cognitive tempo from ADHD in children and adolescents: executive functioning, impairment, and comorbidity. Journal of Clinical Child \& Adolescent Psychology, 42(2), 161-173

Baron, I. S., \& Anderson, P. J. (2012). Neuropsychological assessment of preschoolers. Neuropsychological Review, 22, 311-312.

Bayrami, M., Movahedi, Y., \& Ahmadi, E. (2017). The effectiveness of cognitive rehab on the selectivedivided attention and working memory in students with dyslexia \& dyscalculia disabilities. Neuropsychology, 3(8), 9-28. (Persian)

Blair, C., \& Raver, C. C. (2012). Individual Development and Evolution: Experiential Canalization of Self-Regulation. Developmental Psychology, 48(3), 647-657.

Bodrova, E., \& Leong, D. J. (2007). Tools of the Mind: The Vygotsky Approach to Early Childhood Education (Merrill/Prentice Hall, New York, Ed 2).

Bogdanowicz, k., lockiewicz, M., bogdaniwicz, M., pachalska, M. (2014). Characteristics of cognitive deficits and writing skills of polish adults with developmental dyslexia. International Journal of psychophysiology. No 93, PP: 78-83

Bojczyk, K. E., Davis, A. E., \& Rana, V. (2016). Mother-child interaction quality in shared book reading: Relation to child vocabulary and readiness to read. Early Childhood Research Quarterly, 36, 404-414.

Boros, M., Anton, J., Georgel, C., Grainger, J., Szwed, M., Ziegler, J. (2016). Orthographic processing deficits in developmental dyslexia: Beyond the ventral visual stream. Neuroimaging, 128, 316-327.

Boustanzar, R., \& Rezayi, S. (2017). Developing intervention program focused and divided attention and investigating its effectiveness on working memory IQ in children with specific learning disorder. Journal of Learning Disabilities, 7(1), 7-25. (Persian)

Brosnan, M. Demeter, J., Hamill, S., Robson, K, \& Cody, G. (2002).Executive functioning adults and children with Developmental Dyslexia. Journal of Neuropsychological, 40(12): 44-55.

Buchanan, T. W., \& Adolphs, R. (2002). The role of the human amygdala in emotional modulation of longterm declarative memory. Advances in Consciousness Research, 44, 9-34.' 
Buchanan, T. W., \& Adolphs, R. (2002). The role of the human amygdala in emotional modulation of longterm declarative memory. Advances in Consciousness Research, 44, 9-34.

Bussing, R., Zima, B. T., Mason, D. M., Meyer, J. M., White, K., \& Garvan, C. W. (2012). ADHD knowledge, perceptions, and information sources: perspectives from a community sample of adolescents and their parents. Journal of Adolescent Health, 51(6), 593-600.

Chen, T. Y., \& Chang, G. B. (2004). The relationship between foreign language anxiety and learning difficulties. Foreign Language Annals, 37(2), 279-289.

Davenport, N. D., Karatekin, C., White, T., \& Lim, K. O. (2010). Differential fractional anisotropy abnormalities in adolescents with ADHD or schizophrenia. Psychiatry Research: Neuroimaging, 181(3), 193-198.

Dawson, P., \& Guar, R. (2018). Executive skills in children and adolescents: A practical guide to assessment and intervention. Guilford Publications.

Delavarian, M., Afrooz, G., Towhidkhah, F., Rasoolzadeh, S. K., \& Arjmandnia, A. A. (2016). The Comparison of Visual and Auditory Working Memory between Children at Risk of Neuro/Development Disorders with a Neuro/Cognitive Computerized Program. Journal of Exceptional Children, 15(4), 21-28. (Persian)

Delphi, M., Javadipour; Sh., Delphi, W., Azizi, R., \& Nilforosh, M.H. (2013). Evaluation of cognitive, auditory, language and speech skills in children with cleft lip and palate. Research in Rehabilitation Sciences, 9 (1), 19-11. (Persian)

Dempsey, I., \& Keen, D. (2008). A review of processes and outcomes in family-centered services for children with a disability. Topics in early childhood special education, 28(1), 42-52. Dillon, D. G., \& Pizzagalli, D. A. (2007). Inhibition of action, thought, and emotion: a selective neurobiological review. Applied and Preventive Psychology, 12(3), 99-114.

DeShazo Barry, T., Klinger, L. G., Lyman, R. D., Bush, D., \& Hawkins, L. (2001). Visual selective attention versus sustained attention in boys with Attention-Deficit/Hyperactivity Disorder. Journal of Attention Disorders, 4(4), 193-202.

Dillon, D. G., \& Pizzagalli, D. A. (2007). Inhibition of action, thought, and emotion: a selective neurobiological review. Applied and Preventive Psychology, 12(3), 99-114.

Dispaldro, M., Leonard, L. B., \& Deevy, P. (2013). Real-word and nonword repetition in Italian-speaking children with specific language impairment: A study of diagnostic accuracy. Journal of Speech, Language, and Hearing Research.

Dowson, P. (2017). Graduate Skills. Certificate in Higher Education: Skills for the Workplace Student Yearbook, 355.

Ebrahimi, A., Abedi, A., Faramarzi, S., \& Yarmohamadian, A. (2016). The effectiveness of spectrum project activities on multiple intelligence in preschool children with neuropsychological/ developmental learning disabilities. Advances in Cognitive Sciences, 18 (2), 77-85. (Persian)

Ellingsen, K. M. (2016). Standardized assessment of cognitive development: Instruments and issues. In Early childhood assessment in school and clinical child psychology (pp. 25-49). Springer, New York, NY.

Endlich, NA. (2001). an investigation of the nexus between strategic planning and organization learning. Dissertation for PHD. Title page for ETD etd- 5.1208-1516.

Eriksson, J., Vogel, E. K., Lansner, A., Bergström, F., \& Nyberg, L. (2015). Neurocognitive architecture of working memory. Neuron, 88(1), 33-46.

Faramarzi, S., Shirzadi, P., Qasemi, M., \& Yarmohamadian, A. (2015). The Effect of Neuropsychological 
Interventions on Language Performance of Children with Specific Language Impairment (SLI): A single subject study. Journal of Paramedical Sciences \& Rehabilitation, 4(4), 51-61. (Persian)

Finzi-Dottan, R., Triwitz, Y. S., \& Golubchik, P. (2011). Predictors of stress-related growth in parents of children with ADHD. Research in developmental disabilities, 32(2), 510-519.

Gatica, F. G., Redín, C. I., \& Abaitua, C. R. (2013). Emotional and cognitive profile of adolescents with ADHD: Effects of learning mediated interaction. Procedia-Social and Behavioral Sciences, 84, 1704-1711.

Ghorbanpour, K., Pakdaman, M., Rahmani, M. B., \& Hosseini, Gh. H. (2013). The Effect of Rhythmic Movement and Playing Aerobic on Short-term Memory Functionand Auditory Memory of Students with Iearning Disabilities. Quarterly Journal of Health Breeze, 1(4), 35-44. (Persian)

Hosseinali zade, M., Faramarzi, S., \& Abedi, A. (2019). Developing a package of child-centered interventions and comparing its effectiveness with functional learning on the developmental performance of children with developmental delays. (PhD Dissertation), University of Isfahan, Iran. (Persian)

Hosseinali zade, M., Faramarzi, S., \& Abedi, A. (2019). The effectiveness of neuropsychological early interventions package on motor performance of children with developmental delay. Neuropsychology, 5(17), 9-24. (Persian)

Hudziak, J., \& Archangeli, C. (2017). The future of preschool prevention, assessment, and intervention. Child and Adolescent Psychiatric Clinics, 26(3), 611-624.

Hughes, C. (2011). Changes and challenges in 20 years of research into the development of executive functions. Infant and Child Development, 20, 251-271.

Jafari, S.A., Rezaeian, A., Ghayebie, E., Beyraghi Tossi, M., Mazlom, S.R., \& Rezaei Askarieye, M. (2015). Effect of developmental stimulation on the fine motor development age of toddlers with celiac disease. Evidence Based Care, 5(3), 77-90. (Persian)

Julvez, J., Ribas $\square$ Fitó, N., Forns, M., Garcia $\square$ Esteban, R., Torrent, M., \& Sunyer, J. (2007). Attention behaviour and hyperactivity at age 4 and duration of breast $\square$ feeding. Acta Paediatrica, 96(6), 842-847.

Kakojoibari, A.A., \& Sharifi, A. (2012). Comparison of reading comprehension levels of integrated deaf students with deaf students. Iranian Quarterly of Exceptional Children, 12 (1), 57-47. (Persian)

Kasaeian, K., Kiamanesh, A., \& Bahrami, H. (2014). A comparison of active memory performance and sustained attention among students with and without learning disabilities. Journal of Learning Disabilities, 3(4), 112-123. (Persian)

Kasper, L. J., Alderson, R. M., \& Hudec, K. L. (2012). Moderators of working memory deficits in children with attention-deficit/hyperactivity disorder (ADHD): a meta-analytic review. Clinical psychology review, 32(7), 605-617.

Kavianpour, F., Malekpour, M., \& Abedi, A. (2013). Efficacy of executive functions training (response inhibition) on the rate of impulsivity in preschool children with developmental coordination disorder: A single-subject research. Archives of Rehabilitation, 14 (1), 70-80. (Persian)

King, N., Horrocks, C. (2010). Interviews in qualitative research. London: sage.

Kirby. J. R., \& Das, J. P. (2005). Reading achievement, IQ, and simultaneous-successive processing. Journal of Educational Psychology, 69, 564-570.

Kita, Y., yamanoto, H., oba, K., Trasawa, Y., Moriguchi, Y., uchiyama, H. (2013). Altered brain activity for phonological manipulation in dyslexia Japanese children. Journal of neurology. No 136, PP: 3696-3708.

Kitty, K., Wu, K. K., Anderson, V., \& Castiello, U. (2002). Neuropsychological evaluation of deficits in exec- 
utive functioning for ADHD children with or without learning disabilities. Developmental Neuropsychology, 22(2), 501-531.

Law, M., Hanna, S., King, G., Hurley, P., King, S., Kertoy, M., \& Rosenbaum, P. (2003). Factors affecting family $\square$ centered service delivery for children with disabilities. Child: care, health and development, 29(5), 357-366.

Letts, L., \& Bosch, J. (2005). Measuring occupational performance in basic activities of daily living. Measuring occupational performance: Supporting best practice in occupational therapy.

Lezak, M. D., Howieson, D. B., Loring, D. W., \& Fischer, J. S. (2004). Neuropsychological assessment. Oxford University Press, USA.

Loosli, S., Buschkuehl, M., Perrig, W.J. \& Jaeggi, S.M. (2012).Working memory training improves reading processes in typically developing children, child neuropsychology, 26. (IFirst).

Madrigal, R. (2008). Hot vs. cold cognitions and consumers' reactions to sporting event outcomes. Journal of Consumer Psychology, 18(4), 304-319.

Makarem-Nasab, A., Ghamarani, A., \& Yarmohammadian, A. (2017). The effect of dialogic-based storytelling training on language skills among the girl students with educable intellectual disability in elementary schools. Journal of Research in Rehabilitation Sciences, 13(2), 95-103. (Persian)

Malekpur M. (2003). Early intervention programs for young children with special needs: Theory and practice - A model for Iran. JOEC, 3(1), 39-54. (Persian)

Männel, C., Meyer, L., Wilcke, A., Boltze, J., Kirsten, H., \& Friederici, A. D. (2015). Working-memory end phenotype and dyslexia-associated genetic variant predict dyslexia phenotype. Cortex, 71, 291-305.

McInnes, A., Humphries, T., Hogg-Johnson, S., \& Tannock, R. (2003). Listening comprehension and working memory are impaired in attention-deficit hyperactivity disorder irrespective of language impairment. Journal of abnormal child psychology, 31(4), 427-443.

Meltzer, L. (2018). Executive function in education: From theory to practice. Guilford Publications.

Miller, L. J., Nielsen, D. M., \& Schoen, S. A. (2012). Attention deficit hyperactivity disorder and sensory modulation disorder: a comparison of behavior and physiology. Research in developmental disabilities, 33(3), 804-818.

Milton ,H.(2010). Effects of a computerized working memory training program on attention, working memory, and academics ,in adolescents with severe ADHD/LD, Journal of psychology,1(14),120-122.

Mohammad Esmaeilzadeh, S., AsghariNekah, M., Sharifi, S., Tayarani Niknezhad, H. (2015). The effectiveness of linguistic plays on expressive and receptive language of hearing impaired children. Journal of Paramedical Sciences \& Rehabilitation, 4(1), 7-14. (Persian)

Mousavi, F., \& Gholami, J. (2014). Effects of watching flash stories with or without subtitle and reading subtitles on incidental vocabulary acquisition. Procedia-Social and Behavioral Sciences, 98, 1273-1281. (Persian)

Narimani, M., Soleymani, E., Zahed Babolan, A., \& Abolghasemi, A. (2013). The comparison the effectiveness of executive functionals and play therapy on improving of working memory, attention care and academic achievement in students with math learning disorder. Journal of Clinical Psychology, 5(4), 1-16. (Persian)

Payne, V. G., \& Isaacs, L. D. (2017). Human motor development: A lifespan approach. Routledge.

Ping, M. T. (2014). Group interactions in dialogic book reading activities as a language learning context in preschool. Learning, Culture and Social Interaction, 3(2), 146-158. 
Poon-McBrayer, K. F., \& Wong, P. M. (2013). Inclusive education services for children and youth with disabilities: Values, roles and challenges of school leaders. Children and Youth Services Review, 35(9), 15201525 .

Quinn, K. (2010). Testing for Kindergarten: Simple Strategies to Help Your Child Ace the Tests For: Public School Placement, Private School Admissions, Gifted Program Qualification. Simon and Schuster.'

Quinn, Karen (2014). Preparing children to enter elementary and primary school (translated by A. Abedi and M. Hesam). Isfahan: Neveshteh Publishing.

Reeves, S. L. (2003). Maternal perceptions: The change process during participation in an early intervention program.

Rendall, A. R., Tarkar, A., Contreras-Mora, H. M., LoTurco, J. J., \& Fitch, R. H. (2017). Deficits in learning and memory in mice with a mutation of the candidate dyslexia susceptibility gene Dyx1c1. Brain and language, 172, 30-38.

Rendall, A. R., Tarkar, A., Contreras-Mora, H. M., LoTurco, J. J., \& Fitch, R. H. (2017). Deficits in learning and memory in mice with a mutation of the candidate dyslexia susceptibility gene Dyx1c1. Brain and language, 172, 30-38.

Resnick, R. J. (2005). Attention-deficit/hyperactivity disorder in adults. CB Fisher \& RM Lerner, Encyclopedia of applied developmental science, Thousand Oaks: J Sage Publication, 1, 129-131.

Rey, E., Habchi, O., Mathieu, R., Urquizar, C., Farnè, A., \& Pélisson, D. (2015). Deployment of spatial attention without moving the eyes is boosted by oculomotor adaptation. Frontiers in Human Neuroscience, 9, 426.

Roberts, M. Y., Kaiser, A. P., Wolfe, C. E., Bryant, J. D., \& Spidalieri, A. M. (2014). Effects of the teachmodel-coach-review instructional approach on caregiver use of language support strategies and children's expressive language skills. Journal of Speech, Language, and Hearing Research, 57(5), 1851-1869.

Rothbart, M. K., \& Sheese, B. E. (2007). Temperament and emotion regulation. Handbook of emotion regulation, 331-350.

Sadock, B. (2015). sadock V. Kaplan and Sadock's Comprehensive Textbook of Psychiatry, 1441-1503.

Sen, H.S. (2009). The relationships between the use of metacognitive strategies and reading comprehension. Procedia - Social and Behavioral Sciences, 1, 2301-2305.

Shettleworth, S. J. (2010). Getting around: spatial cognition. Cognition, evolution, and behavior, (2nd ed). Oxford University Press, New York.

Şimşek, Z. C., \& Işıkoğlu Erdoğan, N. (2015). Effects of the dialogic and traditional reading techniques on children's language development. Procedia - Social and Behavioral Sciences 197, 754 - 758.

Smith, K. S., Bucci, D. J., Luikart, B. W., \& Mahler, S. V. (2016). DREADDS: Use and application in behavioral neuroscience. Behavioral Neuroscience, 130(2), 137.

Tafti, M. (2013). A Comparison of auditory selective attention and hearing dominance in students with and without Dyslexia. International Journal of Behavioral Science, 7(3), 215-220.

Tamboer, P., Vorst, H. C. M., Ghebreab, S., \& Scholte, H. S. (2016). Machine learning and dyslexia: Classification of individual structural neuro-imaging scans of students with and without dyslexia. Neuroimaging: Clinical, 11, 508-514.

Teimouri, F., Alhani, F., \& Kazemnejad, A. (2014). The effect of the family-centered empowerment model on the quality of life in parents of children with asthma. Avicenna Journal of Nursing and Midwifery Care, 22 


\section{(3), 5-14. (Persian)}

Thomas, S., Thomas, T., Bosch, R. J., Ramthal, A., Bellinger, D. C., Kurpad, A. V., \& Srinivasan, K. (2019). Effect of maternal vitamin b12 supplementation on cognitive outcomes in south Indian children: a randomized controlled clinical trial. Maternal and child health journal, 23(2), 155-163.

Thomsena, T. (2003). The effects of attention on speech perception: An fMRI study. Journal of Brain and Language, 85, 37-48.

Trute, B., \& Hiebert-Murphy, D. (2007). The implications of "working alliance" for the measurement and evaluation of family-centered practice in childhood disability services. Infants \& Young Children, 20(2), 109-119.

Tseng, W. L., \& Gau, S. S. F. (2013). Executive function as a mediator in the link between attention $\square$ deficit/ hyperactivity disorder and social problems. Journal of Child Psychology and Psychiatry, 54(9), 996-1004.

Verhoeven, L., \& Perfetti, C. A. (2011). Introduction to this special issue: vocabulary growth and reading skill. Scientific Studies of Reading, 15(1), 1-7.

Yarmohammadian, A. (2013). The analysis of relation between learning disorders and language difficulties in elementary school students with learning disabilities. Archives of Rehabilitation, 14 (1), 23-31. (Persian)

Zelazo, P. D., Müller, U., Frye, D., Marcovitch, S., Argitis, G., Boseovski, J., Chiang, J. K., Hongwanishkul, D., Schuster, B. V., \& Sutherland, A. (2003). The development of executive function in early childhood. Monographs of the Society for Research in Child Development, 68(3), vii-137. 